\title{
Post-ablation tubal sterilization syndrome following microwave endometrial ablation
}

Received: 11 March 2006 / Accepted: 28 June 2006 / Published online: 7 September 2006

(C) Springer-Verlag Berlin / Heidelberg 2006

\begin{abstract}
A 45-year-old lady with previous history of laporoscopic sterilization developed bilateral haematosalpinges 3 months post-microwave endometrial ablation (MEA). She subsequently underwent bilateral salpingectomy. This presentation, described as post-ablative tubal sterilization syndrome, has been reported in the literature with different endometrial ablation methods. However, according to our literature search, no case has been reported to date with MEA.
\end{abstract}

Keywords Microwave endometrial ablation ·

Haematosalpinges

\section{Case report}

A 45-year-old lady was referred by her general practitioner as an emergency to the gynaecological unit. She gave a history of colicky lower abdominal pains since she had microwave ablation of the endometrium (MEA) just over 3 months prior to her admission. These pains had progressively worsened but especially so over the few days immediately prior to contacting her GP on the day of her admission. She has had three children, all delivered vaginally. For contraception, she opted for and had laparoscopic Filshie clip tubal sterilization 6 years prior. She had also had an appendectomy at 26 years of age. There was nothing else of significance in her medical history.

Examination on admission revealed stable vital signs. The abdomen was generally soft, but there was mild tenderness on deep palpation on both iliac fossae. Genital

\footnotetext{
A. E. Chukwujama · L. Khalifa · P. K. Mensah

Department of Obstetrics and Gynaecology,

Dumfries and Galloway Royal Infirmary,

Bankend Road,

Dumfries, Scotland, DG1 4AP, UK
}

A. E. Chukwujama $(\bowtie)$

No 32 Brodie Gardens,

Baillieston, Glasgow, G69 6BQ, UK

e-mail: Amen20001@yahoo.com

Fax: +44-0141-7811387 examination showed normal vulva, vagina and cervix with minimal discharge. No vaginal staining or bleeding was noticed. On bimanual examination, the uterus felt bulky with mild tenderness. There was definite tenderness over both adnexa.

Result of laboratory investigations included WBC of $9 \times 10^{9} / 1, \mathrm{Hb}$ of $146 \mathrm{~g} / \mathrm{dl}$ and CRP of $8 \mathrm{~g} / \mathrm{l}$. Urine pregnancy test was negative.

An ultrasound scan performed on the same day reported showed the uterus was bulky and retroverted. There was marked separation of the midline cavity measuring $3.4 \mathrm{~cm}$. This contained some low attenuating heterogeneous material, possibly blood. There was a tubular structure in the right adnexa suggestive of small hydro/pyosalpinx. Both ovaries were difficult to visualize. The patient was counseled and taken to theatre for diagnostic laparoscopy next morning.

Under general anesthesia, the urinary bladder was emptied. An attempt was then made to insert a uterine manipulator but this proved to be difficult on account of a very stenotic cervix. Using Hagar's cervical dilators, the cervix was eventually dilated to $8 \mathrm{~mm}$ resulting in the release of about $100 \mathrm{ml}$ of dark altered blood from the uterine cavity. A uterine curette was used to explore the uterine cavity and a diagnosis of intrauterine synechiae was made. The curette was used to break these adhesions. At the subsequent diagnostic laparoscopy, the findings were bilateral red swollen fallopian tubes medial to the site of the Filshie clips used for sterilization in the past (see Fig. 1). A diagnosis of bilateral haematosalpinx due to retrograde menstruation possibly resulting from the stenosed cervical os and occluded tubes was made. A decision was taken to perform bilateral salpingectomy. This was done laprascopically using Multifire Endo GIA disposable stapler (AutoSuture, United States Surgical). Specimen was retrieved and sent for histological assessment.

The patient made a good recovery and returned home well the next day.

The histology findings showed blood inside both tubes with edema and transmural chronic inflammatory cell infiltrate of the tubal wall confirming the diagnosis of 

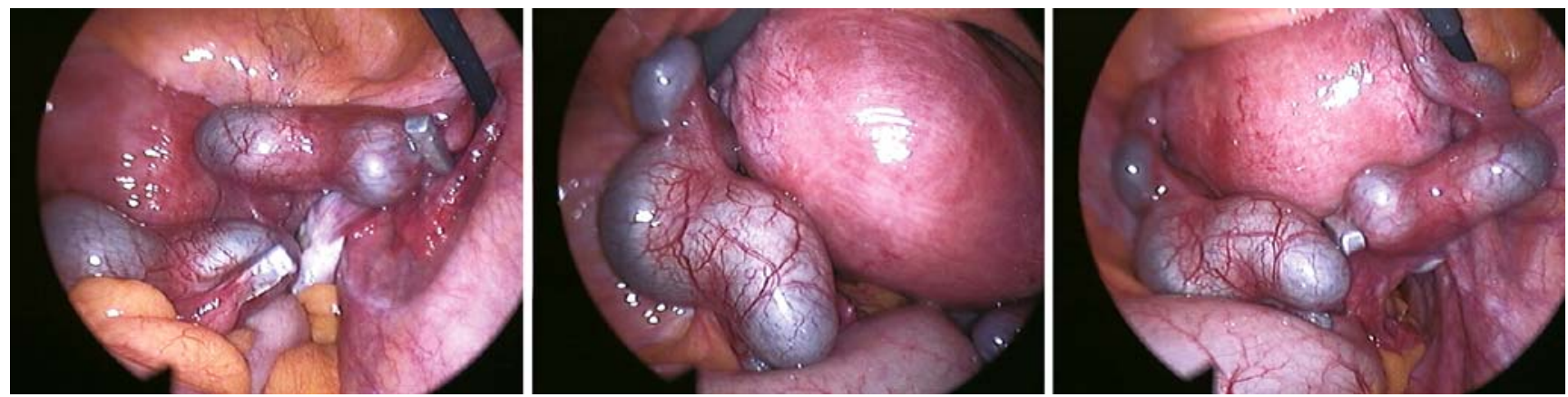

Fig. 1 Laparoscopic views of haematosalpinges with Filshie clips

haematosalpinx. Three months post-operatively, the patient attended a review outpatient appointment. She as asymptomatic. She has had two light menstrual periods since the procedure. Abdominal and pelvic examinations were entirely normal and she was discharged from further follow-up.

\section{Discussion}

Menorrhagia is a common gynaecological problem accounting for $40 \%$ of all gynaecological out-patient consultations.

In the UK, about one in five women will undergo hysterectomy by the age of 60 . In at least half of those who undergo hysterectomies, menorrhagia is the main presenting problem. About half of women who have hysterectomy for menorrhagia have a normal uterus removed [1].

Over the years, several conservative surgical (ablative) techniques have been introduced into clinical practice with the aim of reducing the use of hysterectomy for managing menorrhagia that has not responded to medical therapy. Microwave endometrial ablation (Microsulis Medical, Hampshire, UK) is one of the so-called second-generation endometrial ablation techniques. The early pioneering clinical development of MEA was by Nichola Sharp, who did clinical trials using a prototype in October 1994 [2]. The technique uses a frequency of $9.2 \mathrm{GH}$ to achieve penetration of 5-6 $\mathrm{mm}$ with no spread of microwave energy and no conduction of heat along the applicator.

Various studies comparing the MEA with trans-cervical resection of endometrium (TCRE) and roller-ball technique have consistently shown that the former is a safer, quicker and easier technique with similar efficacy. It avoids hysteroscopic distension media, and risks of earthing and haemorrhage [2-7].

One of the major complications of the ablative procedures is post-ablation tubal sterilization syndrome (PTSS). This was first described by Townsend et al. in 1993. The syndrome consists of lower abdominal pain caused by haematosalpinx and vaginal spotting in women with previous tubal ligation who had undergone hysteroscopic endometrial ablation (roller-ball technique) [8]. These women had distension of the proximal tube caused by occult retrograde bleeding against the obstruction in the tube.
Since then, many authors have published cases of PTSS with different ablative methods [9-11]. Following our extensive literature search we find no reported case of PTSS to date in patients who had MEA.

In the cases reviewed, the earliest time of presentation of this syndrome following the ablative procedure was 5 months. In their review, Bae et al. [10] reported a range of time between 5 and 40 months. In our case, the patient presented earlier, at 3 months post-MEA. We believe that a major contributor to this might be inadvertent treatment of the cervical canal during the microwave ablation of the endometrium.

\section{Conclusion}

MEA is a comparatively safe, quick and efficient endometrial ablation technique. However, short- and long-term follow-up remains important for early detection and treatment of possible complications. It has been highlighted [12] that women undergoing endometrial ablation should be warned of the problem of retrograde menstruation post-procedure, which potentially can lead to heamatosalpinges in women previously sterilized. MEA should not be an exception as illustrated in our case. It is also crucial that all who perform MEA procedure should stick very closely to the treatment protocol to avoid microwaving the cervical canal.

\section{References}

1. Royal College of Obstetricians and Gynaecologists (2004) RCOG national evidence-based clinical guidelines on management of menorrhagia in secondary care. RCOG, London

2. Downes E, O'Donovan P (2000) Microwave endometrial ablation in the management of menorrhagia: current status. Current Opin Obstet Gynecol 12:293-296

3. Cooper K, Brain C, Parkin D (1999) Comparison of microwave endometrial ablation and trans-cervical resection of the endometrium for treatment of heavy menstrual loss: a randomised trial. Lancet 345:1859-1863

4. Parking DE (2000) Microwave endometrial ablation: a safe technique. Gynaecol Endosc 9(6):385-388

5. Hodgson DA, Feldberg IB, Sharp N, Cronin N, Evan M (1999) Microwave endometrial ablation: development, clinical trials and outcomes at three years. Br J Obstet Gynaecol 106:684-694 
6. Cooper JM, Anderson TL, Fortin CA (2004) Microwave endometrial ablation versus roller ball electro ablation for menorrhagia: a multi-centre randomised trial. J Am Assoc Gynaecolog Laparoscop 11(3):394-403

7. Garside R, Stein K, Wyatt K, Round A (2005) Microwave and thermal balloon ablation for heavy menstrual bleeding: a systematic review. BJOG 112(1):12-23

8. Townsend DE, McCausland V, McCausland A (1993) Post ablation tubal sterilization syndrome. Obstet Gynecol 82 (3):422-424
9. Webb JC, Bush MR, Wood MD, Park GS (1996) Hematosalpinx with pelvic pain confirms the postablation-tubal sterilization syndrome. J Am Assoc Gynecolog Laparoscop 3(3):419-421

10. Bae IH, Pagedas AC, Perkings HE, Bae DS (1996) Postablationtubal sterilization syndrome. J Am Assoc Gynecolog Laparoscop 3(3):435-438

11. Sinha P, Pachydakis A, Konamme SP, Auld B (2002) Haematosalpinx and haematometria as long term complication of balloon endometrial ablation. Gynaecol Endosc Vol 11(4):217-219

12. Hill DJ (1994) Hematometra-a complication of endometrial ablation/resection. J Am Assoc Gynecol Laparoscop 1(4):S14 